\title{
Preparation and Optimization of Buccal Propranolol Hydrochloride Nanoethosomal Gel: A Novel Approach for Enhancement of Bioavailability
}

Shahira F. El-Menshawe*, Rasha M. Kharshoum, Amani M. El Sisi

Department of Pharmaceutics and Industrial Pharmacy, Faculty of Pharmacy, Beni-Suef University, Egypt

\begin{abstract}
Propranolol hydrochloride is widely used in the treatment of hypertension and other cardiac conditions. However, the drug is extensively metabolized in the liver. The purpose of this research was to formulate and optimize a nanoethosomal buccal gel of propranolol hydrochloride in an attempt to improve its bioavailability. The ethosomes were prepared using cold method whereas a $2^{3}$ full-factorial design was employed to investigate the effect of phosphatidylcholine (PC), propylene glycol (PG), and ethanol concentration on entrapment efficiency, particle size and \% of drug released. The adjusted and predicted coefficients of determination as well as the CV\% were used to assess the fitness of the experimental model. The optimized formulation F5 containing (1\% PC, 10\% PG and 50\% ethanol) was incorporated in 1\% Carbopol 934 gel base. The buccal gel was evaluated by assessment of the ex vivo drug permeation and in vivo bioavailability. It was noted from regression equations, contour plots and 3D-response surface plots that the three dependent variables had a direct relationship with PC concentration and an inverse relationship with PG and ethanol concentrations. The viscosity of both the ethosomal and control gel which contains the free drug powder was 20745 $\mathrm{cp}$ and $12411 \mathrm{cp}$ respectively. Both gel preparations were homogenous with a pH value of 6.8 . The ethosomal gel exhibited a high flux across a freshly dissected chicken buccal mucosa with an enhancement ratio of 1.314. The mean $\mathrm{AUC}_{0-24}$ for oral tablets, control gel and ethosomal gel were $426.17 \pm 51.78 \mathrm{ng} \cdot \mathrm{hr} / \mathrm{mL}, 579.102 \pm 66.19 \mathrm{ng} . \mathrm{hr} / \mathrm{mL}$ and $810.39 \pm 92.33 \mathrm{ng} . \mathrm{hr} / \mathrm{mL}$ respectively. The relative bioavailability was dramatically enhanced from $135.885 \%$ after using the control gel to $190.157 \%$ with the ethosomal system when compared to the marketed product Inderal ${ }^{\circledR}$ tablet (40 $\mathrm{mg}$ ). The choice of the buccal route together with the use of ethosomes was an appropriate approach to improve the propranolol bioavailability.
\end{abstract}

Keywords: Regression modeling; In vitro characterization; Permeability; First pass metabolism; Relative bioavailability

\section{Introduction}

Treatment of hypertension has received considerable attention over the past decades as hypertension is considered one of the main important factors for developing various cardiovascular diseases such as coronary artery disease and stroke [1,2]. Hence, treatment of hypertension has been considered as an international health requirement $[3,4]$.

Propranolol, which is a nonselective $ß$-adrenergic receptor blocker, is widely used in the treatment of hypertension, angina pectoralis, cardiac arrhythmia and myocardial infarction. However, propranolol hydrochloride (PHCL) is fully absorbed from the gastrointestinal tract after its oral administration, it is subjected to extensive and variable hepatic first pass effect and hence its oral bioavailability was reported to be between $10-30 \%$ [4].

In view of the foregoing, it was apparent that an urgent need exists to formulate PHCL in another dosage form for its appropriate delivery to the systemic circulation. The buccal route has been considered an attractive route for improvement of bioavailability. The buccal mucosa has a high blood perfusion and hence is characterized with 5-8 folds permeability to various pharmacologically active agents if compared with skin [5]. In addition, the buccal route provides an alternative route of administration for drugs that undergoes extensive first pass metabolism or those susceptible to degradation by gastrointestinal enzymes [6].

Although liposomes are considered a potential solution for improvement of tissue permeation, they do not penetrate deeply to the systemic circulation in all cases [7-9]. Thus, new types of lipid vesicles such as transfersomes and ethosomes have been prepared [9].
Transfersomes, were the first type of highly penetrating elastic lipid vesicles introduced $[10,11]$. They are lipid vesicles containing edge activators, which destabilize the lipid bilayer and hence increase the flexibility and penetration $[12,13]$. On the other hand, ethosomes, are lipid carriers composed of phospholipid, ethanol and water [14]. Ethosomes were reported to enhance the permeation by increasing the fluidity of membranes $[9,15]$. The high flexibility of vesicles resulted from the added ethanol permit them to squeeze and penetrate and hence are considered more efficient in delivering drugs [16,17].

For development and optimization of ethosomal formulations, the appropriate combination of different experimental variables must be carefully studied and adjusted [18]. The optimization technique must involve designing a set of experiments that will measure the effect of independent variables on the dependent responses effectively, fitting a mathematical model, conducting an appropriate statistical evaluation of the data, and predicting the independent variable combinations that will produce the best response [19].

*Corresponding author: Elmenshawe SF, Department of Pharmaceutics, Faculty of Pharmacy, Beni-Suef University, Egypt

Elmenshawe SF, Department of Pharmaceutics and Industrial Pharmacy, Faculty of Pharmacy, Beni-Suef University, Egypt, Tel: 201001916181; E-mail: shahira.fawzy@gmail.com

Received: March 23, 2017; Accepted: March 29, 2017; Published: April 05, 2017

Citation: Elmenshawe SF, Kharshom RM, Amani M. El Sisi (2017) Preparation and Optimization of Buccal Propranolol Hydrochloride Nanoethosomal Gel: A Novel Approach for Enhancement of Bioavailability. J Nanomed Nanotechnol 8: 435. doi: 10.4172/2157-7439.1000435

Copyright: (c) 2017 Elmenshawe SF, et al. This is an open-access article distributed under the terms of the Creative Commons Attribution License, which permits unrestricted use, distribution, and reproduction in any medium, provided the original author and source are credited. 
Citation: Elmenshawe SF, Kharshom RM, Amani M. El Sisi (2017) Preparation and Optimization of Buccal Propranolol Hydrochloride Nanoethosomal Gel: A Novel Approach for Enhancement of Bioavailability. J Nanomed Nanotechnol 8: 435. doi: 10.4172/2157-7439.1000435

Page 2 of 9

The aim of this study was to solve the poor bioavailability of PHCL by formulating the drug in a novel buccal nanoethosomal gel. So the practical work in this research was focused on development and optimization of PHCL ehosomal vesicles, in vitro characterization, and finally selection of the best ethosome formulation using Design Expert 8.0.2. The optimized formulation was loaded into a buccal gel to overcome the extensive hepatic metabolism. The in vivo performance of the optimized buccal nanoethosomal was investigated in healthy volunteers.

\section{Material and Method}

\section{Materials}

Soya beans Phosphatidylcholine (PC) was purchased from Across Organics (Geel, Belgium), and propylene glycol (PG) was obtained as a gift from Arabcomed co, Egypt. Carbopol 934 (CP) was obtained from SERVA electrophoresis $\mathrm{GmbH}$, Germany. Dibasic sodium phosphate $\mathrm{Na}_{2} \mathrm{HPO}_{4}$, Potassium dihydrogen orthophosphate $\mathrm{KH}_{2} \mathrm{PO}_{4}$, triethanolamine were all of the pharmaceuticalgrades and were used as received.

\section{Method}

Experimental design: A $2^{3}$ full-factorial design was employed to investigate the joint effect of three independent variables: PC concentration ( 1 and 3\%), PG concentration (10 and 20\%), and ethanol concentration (30 and 50\%) on the dependent variables: entrapment efficiency (EE), particle size and \% of drug released for $12 \mathrm{~h}$ using Design Expert ${ }^{\circ}$ (Version 8.0.2, Stat-Ease Inc. USA). A design matrix comprising of 8 experimental runs was constructed (Table 1).

Experimental model evaluation: The coefficients of determination $\left(\mathrm{R}^{2}\right)$, adjusted and predicted, as well as the $\mathrm{CV} \%$ values were used to evaluate the fitness of the data to the experimental model. The optimized formulation was then selected based on maximum $\mathrm{EE}$, minimum size and maximum $\%$ of PHCL released.

Preparation of PHCL loaded ethosome: PHCL loaded ethosomes were prepared using cold method introduced by Touitou [20]. Briefly, ethosomal suspension was prepared by dissolving PC and PHCL in absolute alcohol under vigorous stirring at room temperature. Then PG followed by water was added portion wise to the previous organic phase under constant mixing at $700 \mathrm{rpm}$. The mixing was continued for 30 minutes at $30^{\circ} \mathrm{C}$ to obtain the required ethosomal suspension.
The suspension was allowed to $\mathrm{cool}$ and then sonicated at $4^{\circ} \mathrm{C}$ for 15 minutes in 3 successive cycles with 5 minutes rest between cycles.

\section{Characterization of PHCL loaded ethosomes}

Determination of particle size (PS): The PS of the prepared formulations were determined by laser scattering technique using Malvern zeta sizer (Zetasizer Ver. 7.11, Malvern Instruments UK) after appropriate dilution with double distilled water. The samples wereadjusted to $25^{\circ} \mathrm{C}$ then subjected to an incident laser beam of 633 $\mathrm{nm}$ at a scattering angle of $90^{\circ}[21]$.

EE determination: Ultracentrifugation method was used for determination of EE. The free unetrapped PHCL was separeted from ethosomal etrapped drug using a cooling centrifuge (Sigma Laborzentrifugen D-37520, Osterode-am-Harz, Germany) at $4^{\circ} \mathrm{C}$ and $15,000 \mathrm{rpm}$ for $2 \mathrm{~h}$ with 15 minutes rest each half an hour. The supernatant containing the free drug was diluted with ethanol and measured with UV spectrophotometer (Shimadzu UV-1800, Japan) at $290 \mathrm{~nm}$. The \% of EE of the vesicles was then calculated, using the following equation:

$$
\% E E=(D T-D S) / D T \times 100
$$

Where DT is the theoretical amount of propranolol and DS is the detected amount.

In vitro release: The in vitro drug release from the prepared vesicles was determined using Franz diffusion cell [22] with $1 \mathrm{~cm}^{2}$ diffusion area and $10 \mathrm{ml}$ receptor cell volume. The receptor compartment was filled with phosphate buffer of $\mathrm{pH} 6.8$ and kept at $37^{\circ} \mathrm{C} \pm 1{ }^{\circ} \mathrm{C}$ under continuous stirring at $100 \mathrm{rpm}$ using magnetic stirrer to simulate the physiological environment [23]. Dialysis membrane was placed between the donor and receptor compartment. Ethosomal suspension was placed in donor compartment and samples were withdrawn through the sampling port of the diffusion cell at pre-planned intervals over $12 \mathrm{~h}$ and analyzed by UV-Visible Spectrophotometer (Shimadzu 1700, Japan) at $290 \mathrm{~nm}$. An equal volume of fresh phosphate buffer ( $\mathrm{pH}$ 6.8) was replaced into the receptor compartment after each sampling.

Responses statistical analysis: In order to analyze the effect of each variable on the designated response; Design Expert 8.0.2. (Stat-Ease Inc., USA) was adopted. Each response coefficient was represented by a Pareto charts to show its statistical significance. Quantitative and qualitative analysis of each variable on each response was assessed. The

\begin{tabular}{|c|c|c|c|c|c|c|}
\hline \multirow[t]{2}{*}{ Formulation code } & \multicolumn{3}{|c|}{ Independent variables } & \multicolumn{3}{|c|}{ Dependent variables(mean \pm SD) } \\
\hline & $\mathrm{X} 1$ & $\mathbf{X} 2$ & $\mathbf{X 3}$ & Y1 & Y2 & Y3 \\
\hline 1 & -1 & -1 & -1 & 90.03 & 470 & 41.63 \\
\hline 2 & 1 & -1 & -1 & 89.38 & 939.1 & 44.38 \\
\hline 3 & -1 & 1 & -1 & 89.58 & 387 & 32.8 \\
\hline 4 & 1 & 1 & -1 & 93.67 & 736.4 & 43.63 \\
\hline 5 & -1 & -1 & 1 & 93.98 & 147 & 34.38 \\
\hline 6 & 1 & -1 & 1 & 91.74 & 308 & 25.63 \\
\hline 7 & -1 & 1 & 1 & 87.13 & 139.4 & 30.63 \\
\hline 8 & 1 & 1 & 1 & 89.58 & 231.8 & 30.38 \\
\hline \multicolumn{3}{|c|}{ Factor } & \multicolumn{2}{|c|}{ Levels used, Actual (Coded) } & & \\
\hline \multicolumn{3}{|l|}{ Independent variables } & \multicolumn{2}{|c|}{ Low (-1) } & \multicolumn{2}{|c|}{ High (+1) } \\
\hline \multicolumn{3}{|c|}{$\mathrm{X} 1=$ Phosphatidylcholine (PC)\%W/V } & \multicolumn{2}{|c|}{1} & \multicolumn{2}{|c|}{3} \\
\hline \multicolumn{3}{|c|}{ X2=Propylene glycol (PG)\%V/V } & \multicolumn{2}{|c|}{10} & \multicolumn{2}{|c|}{20} \\
\hline \multicolumn{3}{|l|}{$\mathrm{X} 3=$ Ethanol $(\% \mathrm{~V} / \mathrm{V})$} & \multicolumn{2}{|c|}{30} & \multicolumn{2}{|c|}{50} \\
\hline
\end{tabular}

Where $\mathrm{Y} 1$ : entrapment efficiency (\%), Y2: particle size (nm), and $\mathrm{Y} 3: \%$ of drug released in $12 \mathrm{~h}$.

Table 1: Full factorial design and measured responses of the propranolol hydrochloride ethosomal formulations. 
Citation: Elmenshawe SF, Kharshom RM, Amani M. El Sisi (2017) Preparation and Optimization of Buccal Propranolol Hydrochloride Nanoethosomal Gel: A Novel Approach for Enhancement of Bioavailability. J Nanomed Nanotechnol 8: 435. doi: 10.4172/2157-7439.1000435

Page 3 of 9

significant polynomial equations generated by Design Expert were used to validate the experimental design [24].

Selection of optimized formulation: Design Expert software was utilized to select the optimized ethosomal formulation on the basis of small PS, high EE, and high in vitro cumulative drug release after $12 \mathrm{~h}$.

Characterization of the optimized formulation: In addition to $\mathrm{PS}, \mathrm{EE}$ and in vitro release additional investigations including electron microscopy, ex vivo permeation and pharmacokinetic studies were performed on selected optimized formulation.

Transmission electron microscopy (TEM): The optimized formulation was examined for its morphological shape. The sample was prepared by placing a drop of PHCL loaded ethosomes that was previously diluted 50 fold with double-distilled water onto a 400 -mesh copper grid coated with carbon film and followed by negative staining with $1 \%$ phosphotungstic acid. The sample was dried in the air before TEM observation [25].

Preparation and characterization of PHCL ethosomalbuccal gel: The optimized PHCL loaded ethosome formulation was incorporated into a buccal gel. Carbopol $934(1 \% \mathrm{w} / \mathrm{v})$ was soaked in minimum amount of water and left overnight. The ethosomal suspensions equivalent to $40 \mathrm{mg}$ was added to the swollen polymer under stirring until homogeneous gels were achieved. The $\mathrm{pH}$ was then adjusted to 6.8 using triethanolamine [22]. Control gel containing $40 \mathrm{mg}$ of PHCL was prepared following the same previous procedure with replacing the ethosomes by the free crude drug.

The viscosity of the produced ethosomal and control gels were measured at $25^{\circ} \mathrm{C}$ using Brookfield viscometer (RV-TD; Brookfield) and the $\mathrm{pH}$ value was measured using a digital $\mathrm{pH}$ meter $(3500 \mathrm{pH}$ meter, Jenway, UK). The homogeneity of the gel formulations were examined by visual appearance and placing a small quantity of the preparation between the thumb and the index finger (Abdellatif and Tawfeek 2015).

Ex vivo permeation studies: Permeation studies were performed on PHCL ethosomal gel and control gel using Franz glass diffusion cell [22] with $1 \mathrm{~cm}^{2}$ diffusion area and $10 \mathrm{ml}$ receptor cell volume. The receptor compartment was filled with phosphate buffer of $\mathrm{pH} 6.8$ and maintained at $37^{\circ} \mathrm{C} \pm 1^{\circ} \mathrm{C}$ under stirring using magnetic stirrer. Freshly dissected chicken buccal mucosa was placed between the donor and receptor compartment. Ethosomal gel equivalent to $40 \mathrm{mg}$ was applied to the surface of the skin. Samples were withdrawn at predetermined time intervals over $12 \mathrm{~h}$ and analyzed by UV-Visible Spectrophotometer (Shimadzu 1700, Japan) at $290 \mathrm{~nm}$. An equal volume of fresh phosphate buffer ( $\mathrm{pH}$ 6.8) was replaced into the receptor compartment after each sample withdrawing. Percentage cumulative amount of PHCL permeated per unit surface area were plotted against time and analyzed using the following Fick's equation [26]:

$$
J_{s s}=\frac{d Q / d t}{A}
$$

Where $\mathrm{J}_{\text {ss }}$ is the steady-state flux; $\mathrm{dQ} / \mathrm{dt}$ is the permeation rate; $\mathrm{A}$ is the active diffusion area $\left(1 \mathrm{~cm}^{2}\right)$.

The enhancement ratio (Er) attributed to ethosome encapsulation was calculated by the following equation [27]:

$$
\mathrm{Er}=\frac{\mathrm{J}_{\mathrm{SS}} \text { of ethosmal gel }}{\mathrm{J}_{\mathrm{ss}} \text { of controled gel }}
$$

The data obtained from the permeation studies were kinetically analyzed and the order of drug permeation from the ethosomal gel was determined. Zero- and first-order kinetics as well as the Higuchi diffusion model was employed and the correlation coefficient values $\left(\mathrm{R}^{2}\right)$ were determined.

Statistical analysis: For the validity of the statistical analysis, all experiments were done in triplicate. Results were presented as mean \pm $\mathrm{SD}$. The results were analyzed using one-way ANOVA with subsequent multiple comparisons using the Tukey multiple comparisons test. Significance level was set at $(\mathrm{p}<0.05)$. All calculations were made using the computer program SPSS 16.0 (SPSS, Chicago, IL).

In vivo pharmacokinetic study: In vivo study was conducted to compare the pharmacokinetic parameters of PHCL from ethosomal gel formulation (Treatment A) and the control gel (Treatment B) with conventional Inderal ${ }^{\circledR}$ tablet ( $40 \mathrm{mg}$ ) - AstraZeneca, Egypt (Treatment C).

Subjects selection: Six healthy male volunteers aged between 30 to 40 years (median weight: $75 \pm 5.3 \mathrm{~kg}$ and median height: $175 \pm 4.8$ $\mathrm{cm}$ ) were chosen. The health status of all volunteers was assessed by taking a complete medical history, as well as a complete hematological and biochemical examination. None of the volunteers had any history of drug or alcohol abuse, nor did they have any acute or chronic gastrointestinal, cardiac, vascular, hepatic or renal disease. The study protocol was reviewed and conducted according to Helsinki agreement protocol and according to the requirements of the ethical committee of Faculty of Pharmacy, Beni-Suief University, Egypt. Each subject read, understood and signed an informed written consent. All subjects were informed about the risks and objectives of the study.

\section{Study design}

A three-period randomized crossover design was performed on three phases using six healthy male volunteers. Formulations were assigned according to a randomization schedule (Table 2). A washout period of 14 days separated each period of the study and the six volunteers received the three treatments. The tested gel formulations were applied to the buccal mucosa at the right side cheek and volunteers were asked to avoid swallowing. The Inderal ${ }^{\circledR}$ tablets were taken with $200 \mathrm{ml}$ water.

\section{Sample collection}

Venous blood samples $(3 \mathrm{~mL})$ were collected into heparinized tubes through an indwelling cannula at $0.5,1,1.5,2,3,4,6,8,10,12$ and $24 \mathrm{~h}$ after administration. The serum was immediately separated from the blood cells by centrifugation at $3500 \mathrm{rpm}$ for 10 minutes and stored at $-20^{\circ} \mathrm{C}$ until analysis.

\begin{tabular}{|c|c|c|c|}
\hline $\begin{array}{c}\text { Volunteer } \\
\text { Number }\end{array}$ & Study period (1) & Study period (2) & Study period (3) \\
\hline 1 & Treatment A & Treatment B & Treatment C \\
\hline 2 & Treatment B & Treatment A & Treatment C \\
\hline 3 & Treatment C & Treatment A & Treatment B \\
\hline 4 & Treatment A & Treatment C & Treatment B \\
\hline 5 & Treatment B & Treatment C & Treatment A \\
\hline 6 & Treatment C & Treatment B & Treatment A \\
\hline
\end{tabular}

Treatment A: PHCL nanoethosomal gel containing PHCL equivalent to $4 \% \mathrm{w} / \mathrm{w}$ treatment $\mathrm{B}$ : control gel containing $4 \% \mathrm{PHCL}$ w/w, treatment $\mathrm{C}$ : Inderal ${ }^{\otimes}$ tablets $40 \mathrm{mg}$.

Table 2: Latin square crossover design for the pharmacokinetic study of PHCL Treatments. 
Citation: Elmenshawe SF, Kharshom RM, Amani M. El Sisi (2017) Preparation and Optimization of Buccal Propranolol Hydrochloride Nanoethosomal Gel: A Novel Approach for Enhancement of Bioavailability. J Nanomed Nanotechnol 8: 435. doi: 10.4172/2157-7439.1000435

\section{Assay method and chromatographic conditions}

Plasma samples were analysed using a modified HPLC method of Rekhi et al. [28]. The mobile phase composed of acetonitrile: $1 \% \mathrm{v} / \mathrm{v}$ aqueous acetic acid containing $0.2 \%$ triethylamine $(35: 65 \mathrm{v} / \mathrm{v})$ and the $\mathrm{pH}$ was adjusted at 3.6 with $0.1 \mathrm{~N}$ sulphuric acid. The mobile phase was filtered, degassed and pumped at flow rate $1 \mathrm{ml} / \mathrm{min}$ with a fluorescence detector set at an excitation wavelength of $290 \mathrm{~nm}$ and an emission wavelength of $358 \mathrm{~nm}$.

\section{Plasma analysis}

Acetonitrile $(2 \mathrm{~mL})$ was added to plasma samples $(200 \mu \mathrm{L})$ for protein precipitation followed by vortexing and centrifugation at 2000 $\mathrm{rpm}$. The clear supernatant was evaporated under a stream of nitrogen at $50-60^{\circ} \mathrm{C}$ until dryness. The residue was dissolved in $200 \mu \mathrm{L}$ of the mobile phase, and then injected into HPLC C18 column $(3.9 \mathrm{~mm} \times 300$ $\mathrm{mm}$, particle size $5 \mu \mathrm{m}$ ), at ambient conditions.

\section{Pharmacokinetic analysis}

Pharmacokinetic parameters from plasma data were determined using, WinNonlin, version 1.5 (Scientific Consulting, Inc. Cary, NCT). Two-way ANOVA was used to assess the significance of the difference between the pharmacokinetic parameters obtained for three treatment formulations at 95\% confidence limit using the SPSS program [29] and the relative bioavailability was determined from the following equation [30]:

$$
\text { Relative bioavailability }=A U C_{(0-24)} / A U C_{(0-24) \text { Refrence }} \times 100
$$

\section{Results and Discussion}

\section{Preparation and study of the effect of formulation variables on PS, EE, and \% of drug released}

The effect of independent variables was presented in Table 1. Contour plots and 3D-response surface were constructed to illustrate the effect of independent variables on dependent ones. Each plot exhibits the effect of two independent factors after fixing the third variable at the high level value (Figures 1 and 2). As ethanol was held constant it was observed that the maximum EE was obtained when PC range (1-2.5\% w/v) and PG (10-12.5\% v/v), minimum size was obtained at PC $(1-1.3 \% \mathrm{w} / \mathrm{v})$ and $\mathrm{PG}(10-20 \% \mathrm{v} / \mathrm{v})$, and maximum release at PC $(1-1.3 \% \mathrm{w} / \mathrm{v})$ and PG $(10-14 \% \mathrm{v} / \mathrm{v})$. As PG was held constant maximum EE was obtained at PC $(2.3-3 \% \mathrm{w} / \mathrm{v})$ and ethanol $(30-36.6 \% \mathrm{v} / \mathrm{v})$, minimum size at PC (1-3\% w/v) and ethanol $(42-50 \%$ $\mathrm{v} / \mathrm{v})$, and maximum release at PC (2.6-3\% w/v) and ethanol $(30-33 \%$ $\mathrm{v} / \mathrm{v})$. As PC held constant Maximum EE was obtained at PG (17-20\% $\mathrm{v} / \mathrm{v})$ and ethanol (30-36\% v/v), minimum size when PG (10-20\% v/v) and ethanol (46-50\% v/v), and maximum release when PG $(10-14.3 \%$ $\mathrm{v} / \mathrm{v})$ and ethanol $(30-33 \% \mathrm{v} / \mathrm{v})$

It was noted from regression equation (Table 3), contour plots and 3D-respnse surface that EE had a positive relationship with PC and negative relationship with PG and ethanol. These results were in agreement with the reported results $[14,16,20,31,32]$. The drug is supposed to be entrapped in the aqueous compartment of the vesicles, and the decrease in the EE may be attributed to the increase in the fluidity of vesicles upon increase in the ethanol content leading to drug leakage [33]. Vesicle size had direct relationship with PC and negative relation with PG and ethanol these results were in agreement with the reported results $[32,34]$. The size reduction with increasing PG and ethanol could be attributed to negatively charge by ethanol which causes electrostatic repulsion and some degree of stearic stabilization. Another explanation is due to interaction of ethanol with lipid bilayers which reduce membrane thickness [17,35]. From Table 1 it was founded that PC increase \% of release while ethanol and PG increase lead to decrease in \% released which could attributed to decrease in EE due to drug leakage.

To evaluate the performance of the model, experimental values did fall close to unity lines when plotted against predicted dependent variables (Figure 3 ) indicating good correlation between dependent and independent variables. Based on the previously determined criteria F5 was selected as optimized formulation (desirability 0.82 ) for further in-vitro and in vivo characterization.

\section{Optimization of propranolol loaded ethosomes}

Design-Expert software was adopted to obtain the optimum values of the independent variables based on desirability criteria. Upon the investigation of various response variables the formulation F5 containing $50 \% \mathrm{v} / \mathrm{v}$ ethanol, $10 \% \mathrm{w} / \mathrm{v}$ PG and $2 \% \mathrm{w} / \mathrm{v}$ PC was found to fulfill the maximum criteria of an optimum formulation as it was characterized by minimum mean vesicle size $(147 \mathrm{~nm})$, maximum EE (93.98\%), maximum RE (34.38\%) values. The optimized formulation was then formulated as buccal ethosomal gel.

\section{Morphology of propranolol loaded ethosome}

TEM image of the optimized PHCL ethosomal formulation was illustrated in Figure 4. The micrographs proved the formation of small rounded vesicles, with uniform size distribution.

\section{Physical characterization of PHCL gels}

The viscosity of both the ethosomal gel and control gel was measured and was found to be higher in the ethosmal gel $(20745 \mathrm{cp})$ than the control one $(12411 \mathrm{cp})$. The increase in viscosity had contributed positively in making the ethosomal gel more suitable for buccal administration and at the same time hinder the fusion of vesicles which may enhance its permeation through buccal mucosa. The high values of viscosity may be attributed to the phosphatidylcholine component of the ethosomes [21].

Both the control and ethosomal gel formulations exhibited a $\mathrm{pH}$ value of $\mathrm{pH} 6.8$ resembling $\mathrm{pH}$ of buccal mucosa. This $\mathrm{pH}$ value was

\begin{tabular}{|c|c|c|c|c|c|}
\hline Response & $\mathbf{R}^{2}$ & Adjusted $\mathbf{R}^{2}$ & Predicted $\mathbf{R}^{2}$ & SD & $\% \mathrm{CV}$ \\
\hline Y1: EE (\%) & 0.99 & 0.99 & 0.99 & 0.018 & 0.02 \\
\hline Y2: PS (nm) & 0.99 & 0.99 & 0.96 & 18.07 & 4.30 \\
\hline Y3: \% release & 0.99 & 0.99 & 0.99 & 0.15 & 0.42 \\
\hline \multicolumn{6}{|c|}{ Regression equation of the fitted quadratic model } \\
\hline \multicolumn{6}{|c|}{$\mathrm{Y} 1=+90.64+0.46 \times \mathrm{x} 1-0.65 \times \mathrm{x} 2-0.029 \times \mathrm{x} 3+1.18 \times \mathrm{x} 1 \times \mathrm{x} 2-0.40 \times \mathrm{x} 1 \times \mathrm{x} 3-1.61 \times \mathrm{x} 2 \times \mathrm{x} 3$} \\
\hline \multicolumn{6}{|c|}{$Y 2=+419.84+133.99 \times x 1-46.19 \times \times 2-213.29 \times \times 3-23.54 \times x 1 \times \times 2-70.64 \times x 1 \times \times 3+25.24 \times x 2 \times x 3$} \\
\hline \multicolumn{6}{|c|}{$Y 3=+35.43+0.57 \times x 1-1.07 \times x 2-5.18 \times x 3+2.07 \times x 1 \times x 2-2.82 \times x 1 \times x 3+1.32 \times x 2 \times x 3$} \\
\hline
\end{tabular}

Table 3: Summary of results of regression analysis for entrapment efficiency (EE), particle size (PS) and percentage drug released after $12 \mathrm{~h}$. 
Citation: Elmenshawe SF, Kharshom RM, Amani M. El Sisi (2017) Preparation and Optimization of Buccal Propranolol Hydrochloride Nanoethosomal Gel: A Novel Approach for Enhancement of Bioavailability. J Nanomed Nanotechnol 8: 435. doi: 10.4172/2157-7439.1000435
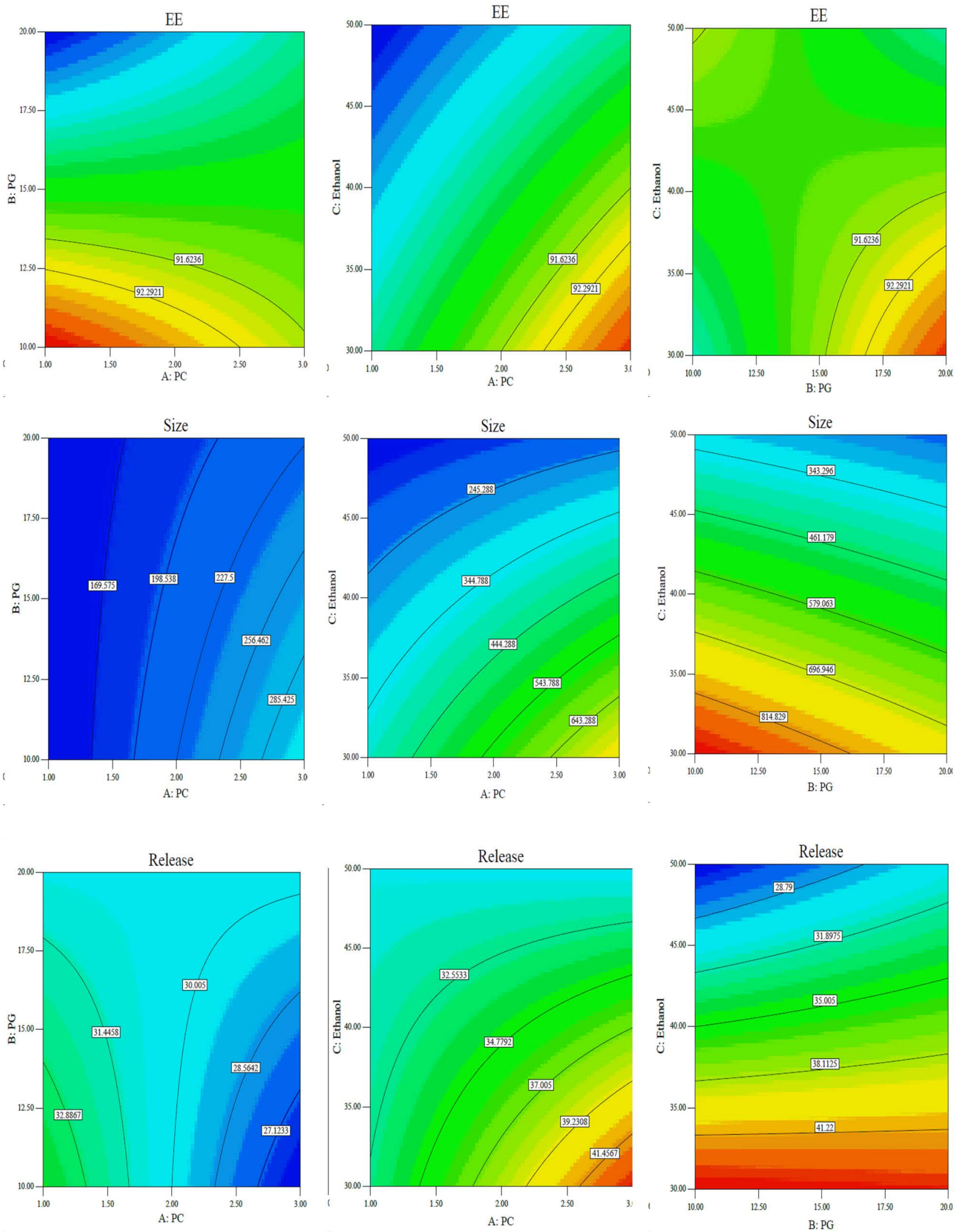

Figure 1: Contour plots showing the effect of phosphatidylcholine concentration (A), propylene glycol concentration (B), and ethanol concentration (C) on entrapment efficiency (EE), particle size (PS) and percentage drug released in $12 \mathrm{~h}$ of PHCL ethosomes. 
Citation: Elmenshawe SF, Kharshom RM, Amani M. El Sisi (2017) Preparation and Optimization of Buccal Propranolol Hydrochloride Nanoethosomal Gel: A Novel Approach for Enhancement of Bioavailability. J Nanomed Nanotechnol 8: 435. doi: 10.4172/2157-7439.1000435
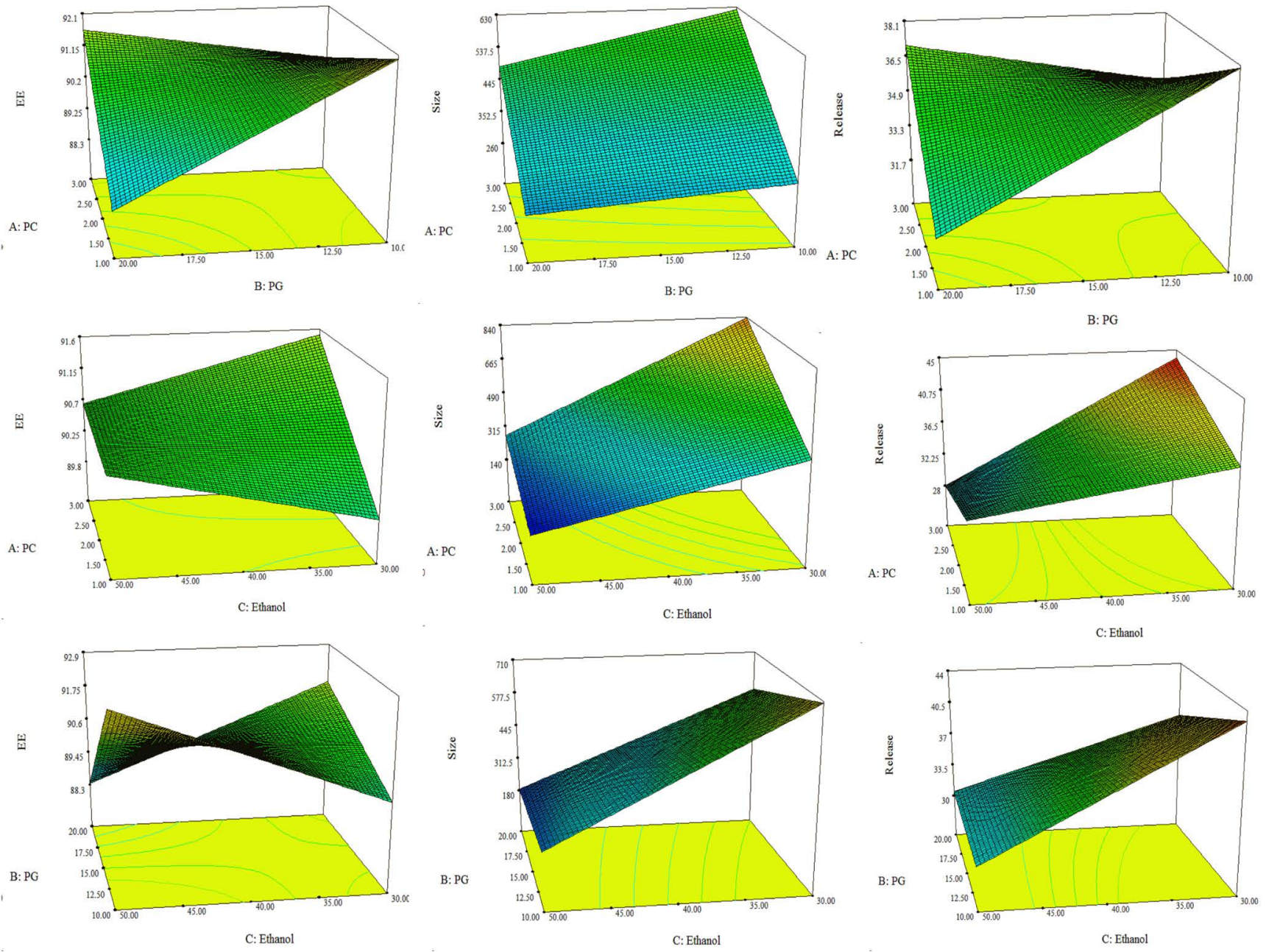

Figure 2: Response surface plots showing the effect of phosphatidylcholine concentration (A), propylene glycol concentration (B), and ethanol concentration (C) on entrapment efficiency (EE), particle size (PS) and percentage drug released in $12 \mathrm{~h}$ of PHCL ethosomes.

\begin{tabular}{|c|c|c|c|}
\hline \multirow{2}{*}{$\begin{array}{c}\text { Pharmacokinetic } \\
\text { parameter }\end{array}$} & $\begin{array}{c}|c| \\
\text { Oral marked } \\
\text { formula }\end{array}$ & Cormulation \\
\hline $\mathrm{C}_{\text {max }}(\mathrm{ng} / \mathrm{ml}) \pm \mathrm{SD}$ & $68.46 \pm 9.62$ & $82.97 \pm 10.35$ & $115.93 \pm 12.87$ \\
\hline $\mathrm{T}_{\max }(\mathrm{hr}) \pm \mathrm{SD}$ & $1.75 \pm 0.25$ & $1.83 \pm 0.237$ & $2.67 \pm 0.47$ \\
\hline $\mathrm{AUC}_{(0-24)}(\mathrm{ng} \cdot \mathrm{hr} / \mathrm{ml}) \pm \mathrm{SD}$ & $426.17 \pm 51.78$ & $579.102 \pm 66.19$ & $810.39 \pm 92.33$ \\
\hline $\mathrm{AUC}_{(0-0)}(\mathrm{ng} \cdot \mathrm{hr} / \mathrm{ml}) \pm \mathrm{SD}$ & $498.94 \pm 54.45$ & $639.94 \pm 71.13$ & $882.166 \pm 95.278$ \\
\hline $\mathrm{K}\left(\mathrm{hr}-{ }^{1}\right)$ & 0.0751 & 0.0743 & 0.076 \\
\hline $\mathrm{t}_{1 / 2}(\mathrm{hr})$ & 6.13 & 6.68 & 7.11 \\
\hline $\begin{array}{c}\text { Relative bioavailability } \mathrm{F}_{\text {abs }} \\
(\%)\end{array}$ & ---------- & 135.885 & 190.157 \\
\hline
\end{tabular}

The marketed product was $(40 \mathrm{mg})$ (Inderal ${ }^{\circledR}$ tablets), the control gel contained (4\% w/w of $\mathrm{PHCL})$, the optimized ethosomal gel contained an equivalent amount of $40 \mathrm{mg} \mathrm{PHCL}$ in each $1 \mathrm{~g}$ gel.

Table 4: Pharmacokinetic parameters of PHCL following the administration of a single oral dose of the market formulation, control gel $(4 \% \mathrm{w} / \mathrm{w})$ and the optimized ethosomal gel containing an equivalent amount of $40 \mathrm{mg}$ PHCL in each $1 \mathrm{~g}$ gel.

considered important to avoid mucosal irritation [36]. Both gels were homogenous with no aggregations.

\section{Ex-vivo permeation studies}

The flux across the dissected chicken buccal mucosa from the
PHCL ethosomal gel and control gel was found to be $1573 \mu \mathrm{g} / \mathrm{cm}^{2} /$ hand $1197 \mu \mathrm{g} / \mathrm{cm}^{2} / \mathrm{h}$ respectively with a permeability enhancement ratio (Er) of1.314 (Figure 5). This permeability enhancement reflects the excellent deformability of the vesicles [17]. The permeation power of the prepared ethosomes may be attributed to the presence of ethanol with PC that had led to an increase in the vesicle flexibility and improve their ability to deform, thereby allowing ethosomes to squeeze through the mucosa [37]. The permeation results were found to fit Higuchi diffusion model.

\section{In vivo pharmacokinetic study}

The pharmacokinetic study was conducted to demonstrate the effect of route of administration and ethosoaml system on PHCL bioavailability compared with the orally administered drug. The plasma concentration profile of the three treatments were illustrated in Figure 6 whereas the pharmacokinetic parameters we shown in Table 4, the mean $\mathrm{C}_{\max }$ estimated from $\mathrm{F}$ and control were $115.93 \pm$ $12.87 \mathrm{ng} / \mathrm{ml}, 82.97 \pm 10.35 \mathrm{ng} / \mathrm{ml}$ respectively, while it was $68.46 \pm 9.62$ $\mathrm{ng} / \mathrm{ml}$ for Inderal ${ }^{\circ}$ tablets. The mean value of $\mathrm{AUC}_{0-24}$ which reflects the total amount of drug absorbed over the $24 \mathrm{~h}$ time period for oral tablets, control gel and $\mathrm{F}$ was found to be $426.17 \pm 51.78 \mathrm{ng} . \mathrm{hr} / \mathrm{mL}$, 

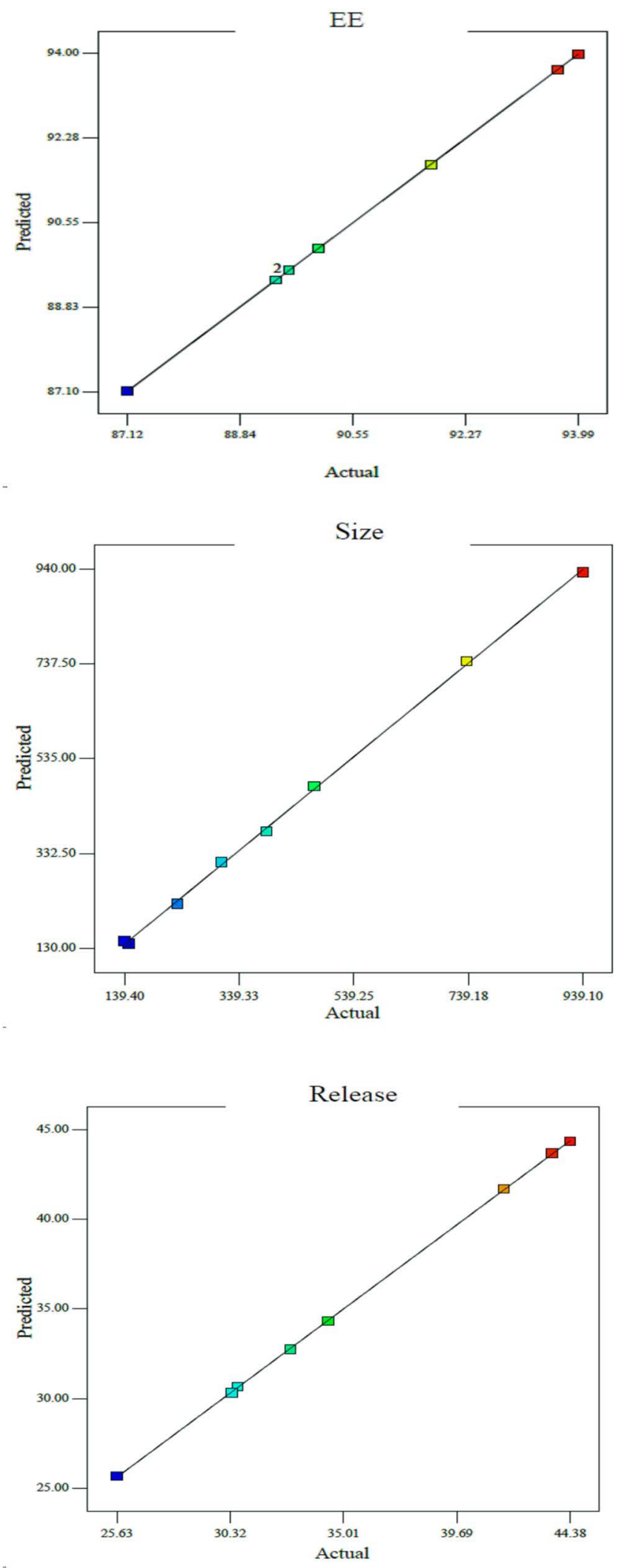

Figure 3: Linear correlation plot between adjusted and predicted values of coefficient of determination. 
Citation: Elmenshawe SF, Kharshom RM, Amani M. El Sisi (2017) Preparation and Optimization of Buccal Propranolol Hydrochloride Nanoethosomal Gel: A Novel Approach for Enhancement of Bioavailability. J Nanomed Nanotechnol 8: 435. doi: 10.4172/2157-7439.1000435

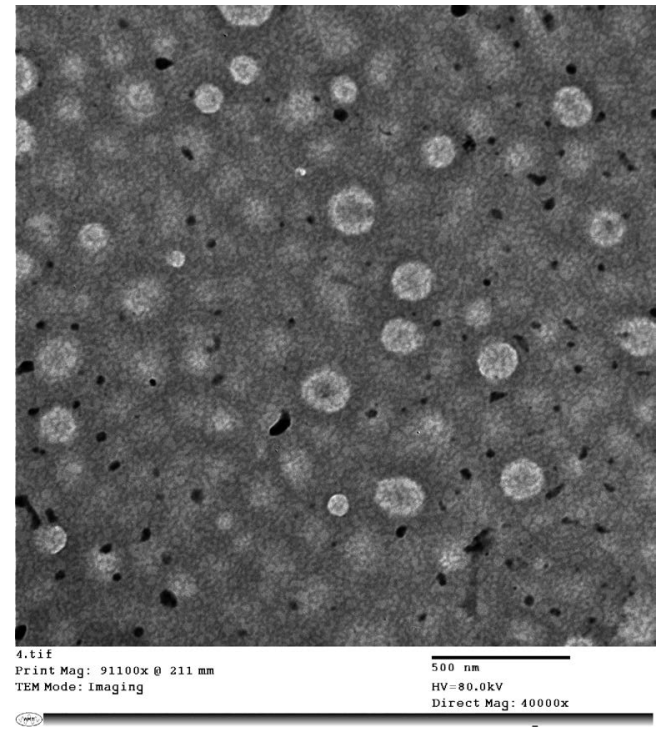

Figure 4: TEM image of the optimized propranolol hydrochloride ethosomes.

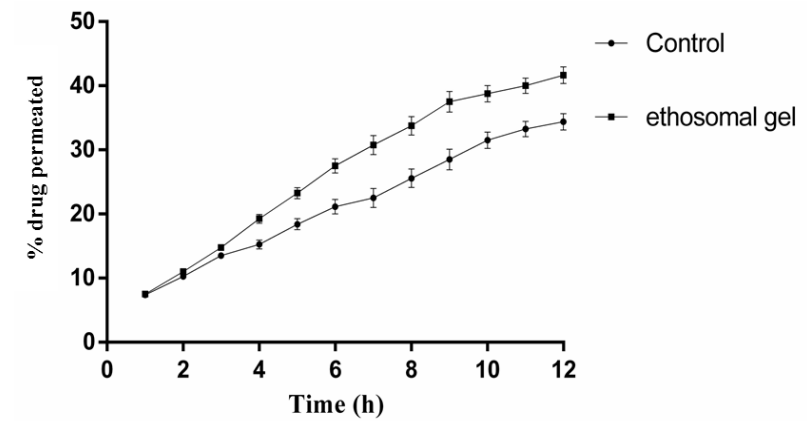

Figure 5: Cumulative percentage permeated of propranolol hydrochloride from control gel containing the free drug and nanoethosomal gel.

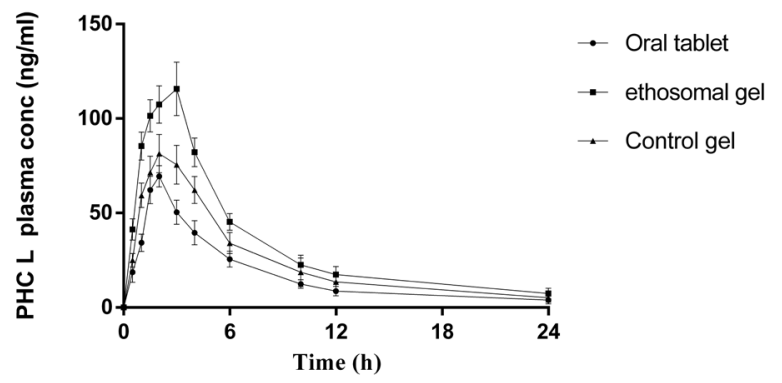

Figure 6: The plasma profile of Inderal ${ }^{\circledR}$ tablets $(40 \mathrm{mg})$, the control gel contained $(4 \% \mathrm{w} / \mathrm{w}$ of $\mathrm{PHCL})$, the optimized ethosomal gel contained an equivalent amount of $40 \mathrm{mg} \mathrm{PHCL}$ in each $1 \mathrm{~g}$ gel.

$579.102 \pm 66.19 \mathrm{ng} . \mathrm{hr} / \mathrm{mL}$ and $810.39 \pm 92.33 \mathrm{ng} . \mathrm{hr} / \mathrm{mL}$ respectively, and the difference was found to be statistically significant at $(\mathrm{p}<0.05)$ demonstrating improved bioavailability. The improved bioavailability via the buccal route was attributed to the avoidance of extensive first pass effect presystemic metabolism. Moreover, the relative bioavailability was dramatically enhanced from $135.885 \%$ after using the control gel to $190.157 \%$ with the ethosomal system which may be attributed to the positive impact of the ethosomes on drug permeability and penetration across the mucosal layers $[14,30]$.

\section{Conclusion}

The ethosomal system was capable of delivering PHCL efficiently through the buccal mucosa, thus improving the relative bioavailability of the drug when compared to the gel containing the free drug administered by the same route. The enhanced bioavailability of the nanoethosomalbuccal gel compared to the oral route may be attributed to the by-pass of the hepatic metabolism and increase of permeation. The nanoethosomes delivered by the buccal route was found to be a potential approach to deliver PHCL much more efficient than oral route.

\section{References}

1. Campbell N, Drouin D, Legowski B, Adams MA, Farrell J, et al. (2012) A framework for discussion on how to improve prevention, management, and control of hypertension in Canada. Canadian Journal of Cardiology 28: 262-269.

2. Prospective S (2002) Age-specific relevance of usual blood pressure to vascular mortality: a meta-analysis of individual data for one million adults in 61 prospective studies. The Lancet 360: 637-646.

3. Kearney PM, Whelton M, Reynolds K, Whelton PK, He J (2004) Worldwide prevalence of hypertension: a systematic review. Journal of hypertension 22 11-19.

4. Ralston $\mathrm{R}$, Lee JH, Truby $\mathrm{H}$, Palermo CE, Walker KZ (2012) A systematic review and meta-analysis of elevated blood pressure and consumption of dairy foods. Journal of human hypertension 26: 3-13.

5. Shojaei AH, Chang RK, Guo X, Couch RA (2001) Systemic drug delivery via the buccal mucosal route. Pharmaceutical Technology 25: 70-81.

6. Kumria R, Nair AB, Al-Dhubiab BE (2014) Loratidine buccal films for allergic rhinitis: development and evaluation. Drug Development and Industrial Pharmacy 40: 625-631.

7. Jain S, Tiwary AK, Sapra B, Jain NK (2007) Formulation and evaluation of ethosomes for transdermal delivery of lamivudine. AAPS Pharmscitech 8: 249-257.

8. Gillet A, Lecomte F, Hubert P, Ducat E, Evrard B, et al. (2011) Skin penetration behaviour of liposomes as a function of their composition. European Journal of Pharmaceutics and Biopharmaceutics 79: 43-53.

9. Song CK, Balakrishnan P, Shim CK, Chung SJ, Chong S, et al. (2012) A nove vesicular carrier, transethosome, for enhanced skin delivery of voriconazole: characterization and in vitro/in vivo evaluation. Colloids and Surfaces B Biointerfaces 92: 299-304.

10. Cevc G, Blume G (1992) Lipid vesicles penetrate into intact skin owing to the transdermal osmotic gradients and hydration force. Biochimica et Biophysica Acta (BBA)-Biomembranes 1104: 226-232.

11. Bendas ER, Tadros MI (2007) Enhanced transdermal delivery of salbutamo sulfate via ethosomes. AAPS Pharmscitech 8: 213-220.

12. El Maghraby G, Williams AC, Barry B (2004) Interactions of surfactants (edge activators) and skin penetration enhancers with liposomes. International journal of pharmaceutics 276: 143-161.

13. Honeywell-Nguyen PL, Frederik PM, Bomans PH, Junginger HE, Bouwstra JA (2002) Transdermal delivery of pergolide from surfactant-based elastic and rigid vesicles: characterization and in vitro transport studies. Pharmaceutical research 19: 991-997.

14. Touitou E, Dayan N, Bergelson L, Godin B, Eliaz M (2000) Ethosomes-Nove vesicular carriers for enhanced delivery: characterization and skin penetration properties. Journal of Controlled Release 65: 403-418.

15. Elsayed MM, Abdallah OY, Naggar VF, Khalafallah NM (2006) Deformable liposomes and ethosomes: mechanism of enhanced skin delivery. International Journal of Pharmaceutics 322: 60-66.

16. Touitou E, Godin B, Shumilov M, Bishouty N, Ainbinder D, et al. (2008) Efficacy and tolerability of clindamycin phosphate and salicylic acid gel in the treatment 
Citation: Elmenshawe SF, Kharshom RM, Amani M. El Sisi (2017) Preparation and Optimization of Buccal Propranolol Hydrochloride Nanoethosomal Gel: A Novel Approach for Enhancement of Bioavailability. J Nanomed Nanotechnol 8: 435. doi: 10.4172/2157-7439.1000435

of mild to moderate acne vulgaris. Journal of the European Academy of Dermatology and Venereology 22: 629-631.

17. Verma P, Pathak K (2012) Nanosized ethanolic vesicles loaded with econazole nitrate for the treatment of deep fungal infections through topical gel formulation. Nanomedicine: Nanotechnology, Biology and Medicine 8: 489-496.

18. Nayak AK, Pal D (2011) Development of pH-sensitive tamarind seed polysaccharide-alginate composite beads for controlled diclofenac sodium delivery using response surface methodology. International Journal of Biological Macromolecules 49: 784-793.

19. Malakar J, Sen SO, Nayak AK, Sen KK (2012) Formulation, optimization and evaluation of transferosomal gel for transdermal insulin delivery. Saudi Pharmaceutical Journal 20: 355-363.

20. Touitou E, Godin B, Dayan N, Weiss C, Piliponsky A, et al. (2001) Intracellular delivery mediated by an ethosomal carrier. Biomaterials 22: 3053-3059.

21. Abdellatif AA, Tawfeek HM (2015) Transfersomal Nanoparticles for enhanced transdermal delivery of clindamycin. AAPS Pharm SciTech: 1-8.

22. Ahmed S, Sarim IS, Zafar A, Ali A, Aqil M, et al. (2016) In vitro and preclinica assessment of factorial design based nanoethosomes transgel formulation of an opioid analgesic. Artificial Cells, Nanomedicine, and Biotechnology 44: 1793-1802.

23. Elkomy MH, Elmenshawe SF, Eid HM, Ali AM (2016) Topical ketoprofen nanogel: artificial neural network optimization, clustered bootstrap validation, and in vivo activity evaluation based on longitudinal dose response modeling. Drug Delivery 23: 3294-3306.

24. Aungst BJ (2000) Intestinal permeation enhancers. Journal of Pharmaceutical Sciences 89: 429-442.

25. Aboud HM, El Komy MH, Ali AA, El Menshawe SF, Abd Elbary A (2016) Development, optimization, and evaluation of carvedilol-loaded solid lipid nanoparticles for intranasal drug delivery. AAPS PharmSciTech 17: 1353-1365.

26. Salih OS, Samein LH, Ali WK (2013) Formulation and in vitro evaluation of rosuvastatin calcium niosomes. International Journal of Pharmacy and Pharmaceutical Science 5: 525-535.

27. Soliman SM, Abdelmalak NS, El-Gazayerly ON, Abdelaziz N (2016) Novel non- ionic surfactant proniosomes for transdermal delivery of lacidipine: optimization using 23 factorial design and in vivo evaluation in rabbits. Drug Delivery 23 1608-1622.

28. Rekhi GS, Jambhekar SS, Souney PF, Williams DA (1995) A fluorimetric liquid chromatographic method for the determination of propranolol in human serum/ plasma. Journal of Pharmaceutical and Biomedical Analysis 13: 1499-1505.

29. Meyyanathan S, Maralidharan S, Rajan S, Gopal K, Suresh B (2008) A simple sample preparation with HPLC-UV method for estimation of amlodipine from plasma: Application to bioequivalence study. The Open Chemical and Biomedical Methods Journal 1: 22-27.

30. Jaiswal PK, Kesharwani S, Kesharwani R, Patel DK (2016) Ethosome: A new technology used as topical \& transdermal delivery system. Journal of Drug Delivery and Therapeutics 6: 7-17.

31. Paolino D, Cosco D, Muzzalupo R, Trapasso E, Picci N, et al. (2008) Innovative bola-surfactant niosomes as topical delivery systems of 5-fluorouracil for the treatment of skin cancer. International Journal of Pharmaceutics 353: 233-242.

32. Morsi NM, Aboelwafa AA, Dawoud MH (2017) Enhancement of the bioavailability of an antihypertensive drug by transdermal protransfersomal system: formulation and in vivo study. Journal of Liposome Research.

33. Ahad A, Raish M, Al-Mohizea AM, Al-Jenoobi FI, Alam MA (2014) Enhanced anti-inflammatory activity of carbopol loaded meloxicam nanoethosomes gel. International Journal of Biological Macromolecules 67: 99-104.

34. Faisal W, Soliman GM, Hamdan AM (2016) Enhanced skin deposition and delivery of voriconazole using ethosomal preparations. Journal of Liposome Research 19: 1-8.

35. López-Pinto JM, González-Rodríguez ML, Rabasco AM (2005) Effect of cholesterol and ethanol on dermal delivery from DPPC liposomes. International Journal of Pharmaceutics 298: 1-12.

36. Ahad A, Aqil M, Kohli K, Sultana Y, Mujeeb M (2015) The ameliorated longevity and pharmacokinetics of valsartan released from a gel system of ultradeformable vesicles. Artificial Cells Nanomedicine and Biotechnology.

37. Verma P, Pathak K (2010) Therapeutic and cosmeceutical potential of ethosomes: An overview. Journal of Advanced Pharmaceutical Technology and Research 1: 274-282. 